silver are obtained in small amounts in lab scale experiments.

- The XRD and FESEM-EDAX studies of the metallic product in the present investigation confirm the presence of gold and silver after aqua leaching of e-waste sample.

- TEM-EDX study analysis shows that leached residue also confirms the presence of gold $(\mathrm{Au})$ and silver (Ag).

- The expenditure for the present study was calculated for $1 \mathrm{~kg}$ of e-waste sample. It shows that the total value of gain product gives a gain amount Rs 381 (in Indian currency Rupees) with an expenditure of Rs 105 for performing such small experiments. However, the expenditure as well as consumption of such an experiment will certainly come down in a continuous large scale operation, which makes the process more economical. Moreover, air instead of $\mathrm{H}_{2} \mathrm{O}_{2}$ as an oxidizing agent; will also cut down the cost further.

- The entire investigation shows that microwave heat treatment is not only a clean process but also an ecofriendly process for obtaining valuable precious metals like gold and silver metals from e-waste.

1. Khanna, R., Cayumil, R., Mukherjee, P. S. and Sahajwalla, V., A novel recycling approach for transforming waste printed circuit boards into a material resource. Proc. Environ. Sci., 2014, 21, 4254.

2. Cui, J. and Zhanga, L., Metallurgical recovery of metals from electronic waste: a review. J. Hazard. Mater., 2008, 158, 228256.

3. Dey, S. and Jana, T., E-waste recycling technology patents filed in India - an analysis. J. Intell. Prop. Rights, 2014, 19, 315-324.

4. Buekens, Alfons and Jie, Y., Recycling of WEEE plastics: a review. J. Mater. Cycles Waste, 2014, 16, 415-434

5. Balde, K., The Global E-waste Monitor 2014 - Quantities, flows and resources. United Nation University; https://i.unu.edu/media/ unu.edu/news/52624/UNU-1stGlobal-E-Waste-Monitor-2014-small. pdf

6. Pant, D., Joshi, D., Manoj Upreti, K. and Ravindra, K. K., Chemical and biological extraction of metals present in e-waste: a hybrid technology. Waste Manage., 2012, 32, 979-990.

7. Chaurasia, A., Singh, K. K. and Mankhand, T. R., Extraction of tin and copper by acid leaching of PCBs. Int. J. Metall. Eng., 2013, 2(2), 243-248.

8. Bala, I. A. K. and Hassan, M. A. A., Thermal plasma treatment of wastes: a review. Aust. J. Basic Appl. Sci., 2015, 9(31), 322-333.

9. Biswajit, R., Thermal plasma treatment of mobile phone waste under reduced condition. Int. J. Environ. Sci., 2012, 2(4), 1-8.

10. Cerqueira, N., Vandensteendam, C., Baronnet, J. M. and Girold, C., Heavy metals volatility during thermal plasma vitrification of mineral waste. Environ. Eng. Sci., 2004, 21(1), 83-92.

11. Abdul, K., Rhamdhani, M. A., Brooks, G. and Syed, M., Metal extraction processes for electronic waste and existing industrial routes: a review and Australian perspective. Resources, 2014, 3, $152-179$.

12. Cheng, T. W., Chu, J. P., Tzeng, C. C. and Chen, Y. S., Treatment and recycling of incinerated ash using thermal plasma technology. Waste Manage., 22(5), 485-490.

13. Srikant, S. S., Mukherjee, P. S. and Rao, R. B., Morphological characterization of titania slag obtained from red sediment placer ilmenite using microwave energy. J. Inst. Eng. India Ser. D, 2015, 96, 43-49
14. Srikant, S. S., Mukherjee, P. S. and Rao, R. B., Prospects of microwave energy in material and mineral processing. Turk. J. Eng. Sci. Technol., 2013, 2, 23-31.

15. Pickles, C. A., Microwaves in extractive metallurgy: Part $1-\mathrm{A}$ review of fundamental. Miner. Eng., 2009, 22, 1102-1111

16. Srikant, S. S., Mukherjee, P. S. and Rao, R. B., Microwave energy for waste management. Mineral Process. Technol., 2013, 3, 948953.

17. Srikant, S. S., Mahapatra, R. P. and Laxmi, T., Microwave energy for waste used engine oil. The Institution of Engineers (India) Odisha State J., 2015, 1, 255-261.

ACKNOWLEDGEMENTS. We are grateful to the Director, Scientists and Researchers of CSIR-Institute of Minerals and Materials Technology, Bhubaneswar for extending the facilities to carry out the work and for the guidance provided. The views and opinions expressed in this paper are purely those of the authors and may not be of those who were involved during the study and preparation of the manuscript. This study did not receive any specific grant from funding agencies in the public, commercial or not-for-profit sectors.

Received 4 August 2018; revised accepted 11 October 2018

\section{Anti-inflammatory activity of synthesized diarylpentenedione derivatives and their drug delivery with silicon-nanotube $(7,7)$}

\author{
A. Surendar ${ }^{1}$, S. K. Sadulla ${ }^{1}$, Ali Noory Fajer ${ }^{2}$, \\ Mazhar Abbas ${ }^{3}$ and Meysam Najafi ${ }^{4, *}$ \\ ${ }^{1}$ School of Electronics, Vignan's Foundation for Science, \\ Technology and Research, Guntur 522 213, India \\ ${ }^{2}$ Department of Biology, Education College, \\ University of Al-Qadisiyah, Al Diwaniyah, Qadisiyyah, Iraq \\ ${ }^{3}$ Department of Management Sciences, COMSATS University, \\ Islamabad Vehari Campus, Pakistan \\ ${ }^{4}$ Medical Biology Research Center, Kermanshah University of \\ Medical Sciences, Kermanshah 67149-67346, Iran
}

Earlier studies have confirmed that diarylpentenedione derivaties $1 \mathrm{a}$ and $1 \mathrm{c}$ have the highest and the lowest anti-inflammatory activity respectively. In this work, the interactions of diarylpentenedione derivatives 1a-1c with Si-nanotube $(7,7)$ were studied and quantum molecular descriptors of the diarylpentenedione derivatives were calculated. Results showed that 1a-1c can interact with $\mathrm{Si}$-nanotube $(7,7)$ significantly and so their adsorptions were possible from an

*For correspondence. (e-mail: meysamnajafi2016@yahoo.com) 
energetic viewpoint. Results also indicated that adsorption thermodynamic values of 1 a on Si-nanotube $(7,7)$ were higher than those of $1 b$ and $1 \mathrm{c}$. Therefore 1a has the highest chemical potential and electrophilicity index values. Thus the obtained theoretical and published experimental trends of anti-inflammatory activity of 1a-1c were similar.

Keywords: Adsorption energy, anti-inflammatory and chemical potential, diarylpentenedione derivatives, silicon nanotube.

INFLAMMATION is a defensive answer that it includes the defended cells, blood vessels and molecular arbitrator. The aim of inflammation is start to correction of tissue. Anti-inflammatory mentions to treatment of inflammation in body ${ }^{1-3}$. Diarylpentanoid derivatives are potential antiinflammatory drugs to remove the monocyte chemoattractant ${ }^{4-6}$.

Nanoparticles such as silicon nanotubes have large band gaps and high performance to therapeutic drug delivery ${ }^{7-11}$. In the present work, the interactions of diarylpentenedione derivatives 1a-1c (Figure 1) with Si-nanotube $(7,7)$ were studied (Figure 2) to propose new anti-inflammatory drugs.

The chemical potential $\left(\mu=\left(E_{\mathrm{LUMO}}+E_{\mathrm{HOMO}}\right) / 2\right)$, chemical hardness $\left(\eta=\left(E_{\mathrm{LUMO}}-E_{\mathrm{HOMO}}\right) / 2\right)$ and electrophilicity index $\left(\omega=\mu^{2} / 2 \eta\right)$ as quantum molecular descriptors can establish the chemical potential of various drugs. The $\mu$ expresses the constancy of drug in contradiction of electronic configuration variations. $\eta$ characterizes the energy gap of a drug, and therefore drugs with lower $\eta$ values are more reactive. $\omega$ measures the ability of a drug to accept electrons. The interactions between drugs and nanostructures can be examined using the following relation: $\Delta N=\left(\mu_{\mathrm{D}}-\mu_{\mathrm{N}}\right) /\left(2 \eta_{\mathrm{D}}+2 \eta_{\mathrm{N}}\right)$, where $\mu_{\mathrm{D}}$ and $\mu_{\mathrm{N}}$ are the chemical potential of the drugs, while $\eta_{\mathrm{D}}$ and $\eta_{\mathrm{N}}$ are the chemical hardness of the drugs and nanostructures respectively $^{12-14}$.

In this study, the $\mu, \eta, \omega$ and $\Delta N$ values of diarylpentenedione derivatives have been calculated in order to establish the capability of Si-nanotube $(7,7)$ to transmission of diarylpentenedione derivatives 1a-1c. The aim of this work is to: (1) to compare the $\Delta E_{\mathrm{ad}}$ and $\Delta G_{\mathrm{ad}}$ values of 1a-1c on the Si-nanotube $(7,7)$ surface; $(2)$ to study the quantum molecular descriptors of $\mathbf{1 a - 1 c}$ and (3) to also study the anti-inflammatory activity of 1a-1c.

In this study, the geometries of Si-nanotube $(7,7)$, diarylpentenedione derivatives 1a-1c and their complexes with Si-nanotube $(7,7)$ via $6-31 G(d)$ basis set and density functional theory method in GAMESS package were optimized $^{15-18}$. The interaction values of $\mathbf{1 a - 1 c}$ and Si-nanotube $(7,7)$ were calculated as

$$
\begin{aligned}
\Delta E_{\mathrm{ad}}= & E(\text { Si-nanotube }(7,7) / \mathrm{drug})-E(\mathrm{drug}) \\
& -E(\operatorname{Si}-\text { nanotube }(7,7))+E_{\mathrm{BSSE}},
\end{aligned}
$$

$$
\begin{aligned}
\Delta G_{\mathrm{ad}}= & G(\text { Si-nanotube }(7,7) / \mathrm{drug})-G(\mathrm{drug}) \\
& -G(\operatorname{Si}-\text { nanotube }(7,7))+E_{\mathrm{BSSE}} .
\end{aligned}
$$

where $E$ (Si-nanotube $(7,7) / \mathrm{drug})$ corresponds to the energy of complexes of 1a-1c with Si-nanotube $(7,7)$; and $E$ (Si-nanotube $(7,7)$ ) and $E$ (drug) correspond to energy of 1a-1c and Si-nanotube $(7,7)$ respectively; G (Si-nanotube $(7,7) / \mathrm{drug}$ ) corresponds to the free Gibbs energy of complexes of $\mathbf{1 a - 1 c}$ with $\mathrm{Si}$-nanotube $(7,7)$ and $G$ (Si-nanotube $(7,7)$, and $G$ (drug) correspond to the free Gibbs energy of $\mathbf{1 a - 1 c}$ and Si-nanotube $(7,7)$ respectively. $E_{\mathrm{BSSE}}$ is the basis set superposition error energy by counterpoise modification method. Negative values of $\Delta E_{\text {ad }}$ and $\Delta G_{\text {ad }}$ correspond to exothermic adsorption of $\mathbf{1 a}-\mathbf{1 c}$ on the surface of Si-nanotube (7,7) (ref. 19).

Leong et al. ${ }^{20}$ synthesized a chain of diarylpentenedione derivatives (1a-1c) and examined their anti-inflammatory activity against RAW 264.7 cell using experimental methods (Figure 1). They showed that diarylpentenedione derivative 1a has the highest action against RAW 264.7 cell, while diarylpentenedione derivative 1c has the highest $\mathrm{IC}_{50}$ value and the lowest action against RAW 264.7 cell $^{20}$. Thus the anti-inflammatory activity of these diarylpentenedione derivatives can be represented as follows: $\mathbf{1 c}<\mathbf{1 b}<\mathbf{1 a}$.

Leopoldini et $a .^{21}$ examined the theoretical parameters of several phenolic drugs using the DFT/B3LYP method. Nam et al. ${ }^{22}$ studied the theoretical parameters for pyridinethiol derivatives using the DFT/B3LYP method, while Mohajeri and Asemani ${ }^{23}$ examined those of chroman derivatives using DFT method.

Researchers $^{21-23}$ showed that DFT/B3LYP method can calculate the experimental activity of drugs, significantly. Rimarcik et al. ${ }^{24}$ studied the activity of several anilines using the B3LYP method. Brinck et al. ${ }^{25}$ calculated the activity of the drugs via DFT/B3LYP and $6-31 \mathrm{G}(d, p)$ basis set. They confirmed there are linear dependencies between the experimental and theoretical activities of studied drugs.

Klein and co-workers ${ }^{26-28}$ confirmed using the theoretical and experimental methods that antioxidant activity

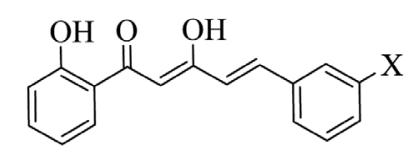

\begin{tabular}{|c|l|c|}
\hline Derivative & $\mathrm{X}$ & Nitric oxid inhibition \\
\hline 1a & $\mathrm{Cl}$ & 26.7 \\
\hline 1b & $\mathrm{Br}$ & 29.4 \\
\hline 1c & $\mathrm{OMe}$ & 31.6 \\
\hline
\end{tabular}

Figure 1. Structures of diarylpentenedione derivatives 1a-1c and published $\mathrm{IC}_{50}$ values (in $\mu \mathrm{M}$ ) against RAW 264.7 cell in previous literature ${ }^{20}$. 

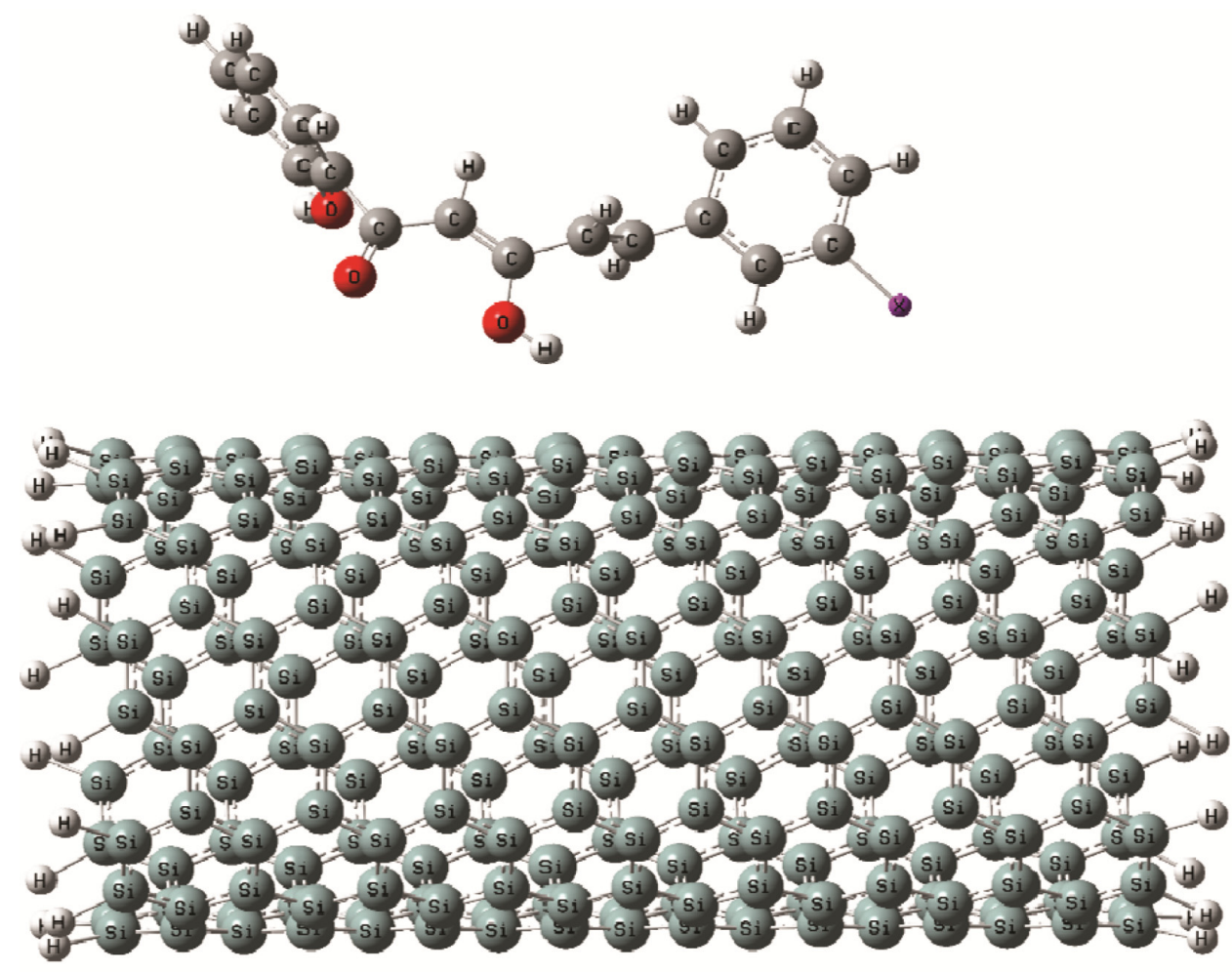

Figure 2. Interactions of diarylpentenedione derivatives 1a-1c with Si-nanotube (7,7).

of drugs such as chromans has linear dependencies. Kumar et al. $^{29}$ studied the properties of naturally occurring flavonoids such as chrysoeriol and hispidulin using DFT/B3LYP.

Sadasivam and Kumaresan ${ }^{30}$ reported that antioxidant activity of drugs via theoretical method (DFT/B3LYP) and experimental scales have same trends. Therefore, it can be concluded that the DFT/B3LP method can predicate the experimental properties of various drugs and also propose novel drugs with high activity ${ }^{21-30}$.

In the present study, the $\Delta E_{\text {ad }}$ and $\Delta G_{\text {ad }}$ values of $1 \mathbf{a}-1 \mathrm{c}$ on Si-nanotube $(7,7)$ surface were calculated. Table 1 shows the $\Delta E_{\mathrm{ad}}$ values of $\mathbf{1 a}$ and $\mathbf{1 b}$ on Si-nanotube $(7,7)$ are higher than that of 1c. Also, the $\Delta E_{\mathrm{ad}}$ value of $\mathbf{1 a}$ on Si-nanotube $(7,7)$ is higher than that of $\mathbf{1 b}$.

The $\Delta G_{\text {ad }}$ value of $1 \mathrm{a}$ on Si-nanotube $(7,7)$ is higher than those of $\mathbf{1 b}$ and $\mathbf{1 c}$ Also, the $\Delta G_{\mathrm{ad}}$ value of $\mathbf{1 b}$ on Si-nanotube $(7,7)$ is higher than that of 1c. $\Delta G_{\text {ad }}$ values of 1a-1c on Si-nanotube $(7,7)$ are lower than $\Delta E_{\mathrm{ad}}$. Thus the results show that $\Delta E_{\mathrm{ad}}$ and $\Delta G_{\mathrm{ad}}$ values of $\mathbf{1 a - 1 c}$ on Si-nanotube $(7,7)$ surface are negative and decrease as follows: 1c $<\mathbf{1 b}<\mathbf{1 a}$. Adsorption of 1a-1c on Si-nanotube $(7,7)$ surface is possible from the thermodynamic viewpoint. The diarylpentenedione derivatives $1 \mathbf{a}$ and 1c have the highest and the lowest probable to Si-nanotube $(7,7)$ respectively.

The diarylpentenedione derivatives $(\mathbf{1 a}-\mathbf{1 c})$ as phenolic structures can play a protective role via three mechanisms. In the first one, the free radical removes a hydrogen atom from 1a-1c. In the second, the diarylpentenedione derivatives can donate an electron to the free radical and drug become a radical cation. In the third, drugs 1a-1c can transfer protons to the free radical and they become anion structures. The bond dissociation enthalpy (BDE), ionization potential (IP) and proton affinity (PA) are important parameters that provide information about the efficiency of the diarylpentenedione derivatives activity. The lower BDE, IP and PA values of 1a-1c increase the reaction of free radical inactivation and electron abstraction $^{20-30}$.

In this study, BDE, IP and PA of 1a-1c were indicated using 6-31G(d) basis set and density functional theory method.

The BDE values of 1a-1c were calculated via differences in enthalpies of diarylpentenedione, hydrogen atom and diarylpentenedione in radical form as follows

$$
\begin{aligned}
\mathrm{BDE}= & \mathrm{H}(\text { diarylpentenedione in radical form }) \\
& -\mathrm{H}(\text { diarylpentenedione })-\mathrm{H} \text { (hydrogen atom }) .
\end{aligned}
$$

The IP values of $\mathbf{1 a}-\mathbf{1 c}$ were calculated via differences of enthalpies in diarylpentenedione, electron and diarylpentenedione in cation radical form as follows

$$
\begin{aligned}
\mathrm{IP}= & \mathrm{H}(\text { diarylpentenedione in cation radical form }) \\
& -\mathrm{H} \text { (diarylpentenedione })-\mathrm{H} \text { (electron) }
\end{aligned}
$$


The PA values of 1a-1c were calculated via differences enthalpies of diarylpentenedione, proton and diarylpentenedione in anion form as follows

$$
\begin{aligned}
\mathrm{PA}= & \mathrm{H} \text { (diarylpentenedione in anion form) } \\
& -\mathrm{H} \text { (diarylpentenedione })-\mathrm{H} \text { (proton) }
\end{aligned}
$$

Table 1 shows the calculated BDE, IP and PA values of 1a-1c. The calculated BDE values of 1a-1c decreased as follows: $\mathbf{1 a}<\mathbf{1 b}<\mathbf{1 c}$. Thus, $\mathbf{1 a}$ has the highest capacity and $1 \mathrm{c}$ has the lowest capacity to lose hydrogen atom.

The calculated IP values of 1a-1c decreased as follows: 1a $<\mathbf{1 b}<\mathbf{1 c}$. Thus 1a has the highest capacity and $1 \mathrm{c}$ has the lowest capacity to lose an electron.

The calculated PA values of 1a-1c decreased as follows: 1a $<\mathbf{1 b}<\mathbf{1 c}$. Thus 1a has the highest capacity and $1 \mathrm{c}$ has the lowest capacity to lose a proton.

Table 2 shows the calculated $\mu, \eta$ and $\omega$ values of 1a-1c and Si-nanotube $(7,7)$. The calculated $\mu$ values of 1a-1c decreased as follows: $1 \mathbf{a}>\mathbf{1 b}>\mathbf{1 c}$. Thus 1a has the highest and 1c has the lowest capacity to accept an electron. The calculated $\eta$ values show that $\mathbf{1 a}$ has the lowest stability and the highest reactivity and $\mathbf{1 c}$ has the lowest reactivity.

The calculated $\omega$ values of $\mathbf{1 a - 1 c}$ decreased as follows: 1a $>1 \mathbf{b}>1 \mathbf{c}$. Thus 1a has the highest and 1c has the lowest capacity to accept electrons.

Table 2 also shows the calculated $\Delta N$ values of complexes of 1a-1c with Si-nanotube $(7,7)$. The diarylpentenedione derivatives $\mathbf{1} \mathbf{a}-\mathbf{1 c}$ act as electron donors and boron nitride-nanotube $(9,9)$ acts as an electron acceptor. Also, 1a has the highest $\Delta N$ value and the highest interactions with $\mathrm{Si}$-nanotube $(7,7)$.

Thus the anti-inflammatory activity of diarylpentenedione derivatives was found to decrease as follows: $\mathbf{1 c}<\mathbf{1 b}<\mathbf{1 a}$. The adsorption potential of $\mathbf{1 a - 1 c}$ decreased as follows: $\mathbf{1 a}>\mathbf{1 b}>\mathbf{1 c}$. Calculations show that

Table 1. Calculated $\Delta E_{\text {ad }}$ and $\Delta G_{\text {ad }}(\mathrm{eV})$ of diarylpentenedione derivatives 1a-1c on surface of Si-nanotube $(7,7)$. The BDE, IP and PA values (eV) of studied structures

\begin{tabular}{lccccc}
\hline Structures & $\Delta E_{\text {ad }}$ & $\Delta G_{\text {ad }}$ & BDE & IP & PA \\
\hline 1a & -0.55 & -0.45 & 11.8 & 17.3 & 8.4 \\
1b & -0.41 & -0.37 & 13.2 & 18.9 & 9.1 \\
1c & -0.34 & -0.26 & 14.6 & 20.1 & 9.9 \\
\hline
\end{tabular}

Table 2. $\mu, \eta, \omega$ and $\Delta N(\mathrm{eV})$ values $\mathbf{1 a}-\mathbf{1 c}$ and Si-nanotube $(7,7)$

\begin{tabular}{lcccc}
\hline Structure & $\mu$ & $\eta$ & $\omega$ & $\Delta N$ \\
\hline Si-nanotube $(7,7)$ & -0.55 & 0.10 & 1.56 & - \\
\hline $\mathbf{1 a}$ & -0.47 & 0.07 & 1.66 & -0.250 \\
$\mathbf{1 b}$ & -0.46 & 0.11 & 0.99 & -0.225 \\
$\mathbf{1 c}$ & -0.45 & 0.14 & 0.73 & -0.217 \\
\hline
\end{tabular}

1a has the highest value and 1c has the lowest $\mu$ and $\omega$ values. It can be concluded that the calculated $\mu, \eta, \omega$ values of 1a-1c and their $\Delta E_{\text {ad }}$ and $\Delta G_{\text {ad }}$ values have similar trends. These theoretical trends confirm the experimental trends of anti-inflammatory activity of $\mathbf{1 a - 1 c}$. The $\Delta E_{\text {ad }}, \Delta G_{\text {ad }}, \mu, \eta$ and $\omega$ values derivatives $1 \mathbf{a}-1 \mathbf{c}$ are vital parameters to predicate their adsorption potential on the Si-nanotube $(7,7)$ surface.

In this study, the anti-inflammatory activity of diarylpentenedione derivatives 1a-1c were examined using theoretical methods and the obtained results were compared with the reported experimental results ${ }^{20}$. Experimental results showed that 1a and 1c have the highest and lowest anti-inflammatory activity respectively. The interactions of 1a-1c with Si-nanotube $(7,7)$ were examined and the quantum molecular descriptors of the diarylpentenedione derivatives were calculated. The adsorption parameters $\left(\Delta E_{\mathrm{ad}}\right.$ and $\left.\Delta G_{\mathrm{ad}}\right)$ of $1 \mathbf{a}-1 \mathbf{c}$ on Si-nanotube $(7,7)$ surface were studied using density functional theory method. Results show that, 1a-1c can interact with $\mathrm{Si}$-nanotube $(7,7)$ significantly and their adsorption on Si-nanotube $(7,7)$ surface is possible from a thermodynamic viewpoint. The adsorption ability of the diarylpentenedione derivatives decreased as follows: $\mathbf{1 a}>\mathbf{1 b}>\mathbf{1 c}$ and 1a. Also, 1a has the highest and 1c the lowest potential for adsorption on Si-nanotube $(7,7)$. In addition, 1 a has the highest $\mu$ and $\omega$ values and the lowest $\eta$ value. Results indicated that theoretical and experimental trends of activity of diarylpentenedione derivatives $\mathbf{1 a}-\mathbf{1 c}$ are similar.

1. Blagg, J., Structure-activity relationships for in vitro and in vivo toxicity. Annu. Rep. Med. Chem., 2006, 41, 353-368.

2. Razavi, R., Hosseini, S. M. A. and Ranjbar, M., Production of nanosized synthetic rutile from ilmenite concentrate by sonochemical $\mathrm{HCl}$ and $\mathrm{H}_{2} \mathrm{SO}_{4}$ leaching. Iran. J. Chem. Chem. Eng., 2014, 33, 29-36.

3. Razavi, R., Kardani, M. N., Ghanbari, A., Lariche, M. J. and Baghban, A., Utilization of LSSVM algorithm for estimating synthetic natural gas density. Petrol. Sci. Technol., 2018, 36, 807-812.

4. Parsaee, Z., Karachi, N. and Razavi, R., Ultrasound assisted fabrication of a novel optode base on a triazine based Schiff base immobilized on TEOS for copper detection. Ultrason. Sonochem., 2018, 47, 36-46.

5. Zahedifar, M., Razavi, R. and Sheibani, H., Reaction of (chloro carbonyl) phenyl ketene with 5-amino pyrazolones: Synthesis, characterization and theoretical studies of 7-hydroxy-6-phenyl-3(phenyldiazenyl) pyrazolo[1,5-a]pyrimidine-2,5(1H,4H)-dione derivatives. J. Mol. Struct., 2016, 1125, 730-735.

6. Karachi, N., Hosseini, M., Parsaee, Z. and Razavi, R., Novel high performance reduced graphene oxide based nanocatalyst decorated with $\mathrm{Rh}_{2} \mathrm{O}_{3} / \mathrm{Rh}-\mathrm{NPs}$ for $\mathrm{CO}_{2}$ photoreduction. J. Photochem. Photobiol. A. Chem., 2018, 364, 344-354.

7. Seyedi, S. H., Saray, B. N. and Nobari, M. R. H., Using interpolation scaling functions based on Galerkin method for solving nonNewtonian fluid flow between two vertical flat plates. Appl. Math. Comput., 2015, 269, 488-496.

8. Moraga, R. J. and Rabiei Hosseinabad, E., A system dynamics approach in air pollution mitigation of metropolitan areas with sustainable development perspective: a case study of Mexico City. J. Appl. Environ. Biol. Sci., 2017, 7, 164-174. 
9. Feili, H. R., Ahmadian, P. and Rabiei, E., Life cycle assessment of municipal solid waste systems to prioritize and compare their methods with multi-criteria decision making. OAJRE, 2014, 39, $1-12$.

10. Azhiri, R. B., Sola, J. F., Tekiyeh, R. M., Javidpour, F. and Bideskan, A. S., Analyzing of joint strength, impact energy, and angular distortion of the ABS friction stir welded joints reinforced by nanosilica addition. Int. J. Adv. Manuf. Technol., 2018, 1, 1-14.

11. Azhiri, R. B., Tekiyeh, R. M., Zeynali, E., Ahmadnia, M. and Javidpour, F., Measurement and evaluation of joint properties in friction stir welding of ABS sheets reinforced by nanosilica addition. Measurement, 2018, 127, 198-204.

12. Ketabchy, M., Sample, D. J., Wynn-Thompson, T. and Yazdi, M. N., Thermal evaluation of urbanization using a hybrid approach. J. Environ. Manage., 2018, 226, 457-475.

13. Joshaghani, M., Ghasemi-Fare, O. and Ghavami, M., Experimental investigation on the effects of temperature on physical properties of sandy soils. IFCEE, 2018, 1, 675-685.

14. Khodabandeh, E., Rozati, S. A., Joshaghani, M., Akbari, O. A., Akbari, S. and Toghraie, D., Thermal performance improvement in water nanofluid/GNP-SDBS in novel design of double-layer microchannel heat sink with sinusoidal cavities and rectangular ribs. J. Therm. Anal. Calorim., 2018, 1, 1-13.

15. Jafarzadeh, F., Jahromi, H. F., Yoosefi, S., Sehizadeh, M., Joshaghani, M. and Alavi, M., Dynamic response of buried gas pipelines due to earthquake induced landslides by nonlinear numerical modeling. In The 15th World Conference on Earthquake Engineering, Beijing, China (15WCEE), 2012.

16. Pourmand, G., Safavi, M., Ahmadi, A., Houdeh, E., Noori, M. Mashhadi, R. and Pourmand, N., A silver lining for early diagnosis of prostate cancer. Urol. J., 2016, 13, 2845-2848.

17. Bakhshi, H., Khodabandeh, E., Akbari, O., Toghraie, D., Joshaghani, M. and Rahbari, A., Investigation of laminar fluid flow and heat transfer of nanofluid in trapezoidal microchannel with different aspect ratios. Int. J. Numer. Method H., 2018, 1, 1-13.

18. Pirbazari, A. E., Monazzam, P. and Kisomi, B. F., Desalin. Co/ $\mathrm{TiO}_{2}$ nanoparticles: preparation, characterization and its application for photocatalytic degradation of methylene blue. Water Treat., 2017, 63, 283-292.

19. Ebrahimian Pirbazari, A., Fakhari Kisom, B. and Ghamangiz Khararoodi, M., Anionic surfactant-modified rice straw for removal of methylene blue from aqueous solution. Desalin. Water Treat., 2016, 57, 18202-18216.

20. Momtazan, M., Niyakan, M., Jaderi, T. and Hoseini Ahangari, S. A., The amount of scientific production of Ahvaz Jundishapur university of medical sciences on pubmed in 2000-2013. Res. J. Med. Sci., 2016, 10, 49-53.

21. Leopoldini, M., Marino, T., Russo, N. and Toscano, M., Antioxidant properties of phenolic compounds: H-atom versus electron transfer mechanism. J. Phys. Chem. A, 2004, 108, 4916-4922.

22. Nam, P. C., Nguyen, M. T. and Chandra, A. K., Assessment of the importance of changes in ground-state energies on the bond dissociation enthalpies of the $\mathrm{O}-\mathrm{H}$ bonds in phenols and the S-H bonds in thiophenols. J. Phys. Chem. A, 2006, 110, 1090410911.

23. Mohajeri, A. and Asemani, S. S., Theoretical investigation on antioxidant activity of vitamins and phenolic acids for designing a novel antioxidant. J. Mol. Struct: (Theochem), 2009, 930, 15-20.

24. Rimarcik, J., Lukes, V., Klein, E., Griesser, M. and Kelterer, A., Theoretical study of structure and electronic properties of cyanosubstituted pyrroles. Chem. Phys., 2008, 353, 177-184.

25. Brinck, T., Haeberline, M. and Jonsson, M., Theoretical study of $\mathrm{X}-\mathrm{H}$ bond energetics $(\mathrm{X}=\mathrm{C}, \mathrm{N}, \mathrm{O}, \mathrm{S})$ application to substituent effects, gas phase acidities, and redox potentials. J. Am. Chem. Soc., 1997, 119, 4239-4244.

26. Klein, E. and Lukes, V., Proton Affinities of para- and metasubstituted phenols in water. Chem. Phys., 2006, 330, 515-525.
27. Najafi, M., Zahedi, M. and Klein, E., DFT/B3LYP study of the solvent effect on the reaction enthalpies of homolytic and heterolytic $\mathrm{OH}$ bond cleavage in mono-substituted chromans. Comput. Theor. Chem., 2011, 978, 16-28.

28. Klein, E., Lukes, V. and Cibulkova, Z., Quantum-chemical study of $\mathrm{C}-\mathrm{H}$ bond dissociation enthalpies of various small non-aromatic organic molecules. J. Mol. Struct.: (Theo-chem.), 2006, 758, 149-159.

29. Kumar, D., Kumar, N. M. and Sundaree, S., A facile synthesis of novel bis-(indolyl)-1,3,4-oxadiazoles as potent cytotoxic agents. Eur. J. Med. Chem., 2010, 45, 1244-1249.

30. Sadasivam, K. and Kumaresan, R., Theoretical investigation on the antioxidant behavior of chrysoeriol and hispidulin flavonoid compounds a DFT study. Comput. Theor. Chem., 2011, 963, 227235 .

Received 8 May 2017; revised accepted 24 October 2018

doi: $10.18520 / \mathrm{cs} / \mathrm{v} 116 / \mathrm{i} 3 / 468-472$

\section{Allocation of biomass and carbon stocks in seven woody species of tropical deciduous forests, Dang, Gujarat}

\section{Ekta Purswani $^{1}$, Bhawana Pathak $^{1, *}$ and Harshad Salvi $^{2}$}

${ }^{1}$ School of Environment and Sustainable Development, Central University of Gujarat, Gandhinagar 382 030, India ${ }^{2}$ Gujarat Ecological Education and Research Foundation, Gandhinagar 382 007, India

Literature on the biomass estimates and carbon cycles of Asian tropical deciduous forests is very limited. In this study, seven woody species were selected, with four representatives each in chronosequence, and harvested from deciduous forests of Dang, Gujarat for assessing their biomass and carbon content. All the species showed a carbon percentage between $40 \%$ and $45 \%$. The regression equations of total biomass versus girth class developed for all seven species would be useful to estimate biomass on a larger scale and the carbon content would improve the understanding about carbon accounts of Indian forests.

Keywords: Biomass estimation, carbon sequestration, climate change, Indian forests, tropical deciduous forests.

ABOUT $17 \%$ of the global $\mathrm{CO}_{2}$ emissions occur due to deforestation and land-use change ${ }^{1}$. Reduction of emissions through deforestation and forest degradation (REDD+)

*For correspondence. (e-mail: bhawana.pathak@cug.ac.in) 